\title{
Use of touch-screen technology to deliver user-focused service improvements in a walk-in sexual health centre
}

\author{
Rachel Paxford-Jenkins, Usha Kumar
}

\section{What did we start with?}

Walk-in reproductive and sexual health services often operate using cumbersome, old-fashioned manual and paper-based systems that restrict users to registering at reception and limit their opportunities for autonomy and engagement in how their needs are managed. Mystery shoppers ${ }^{1}$ provided valuable insight into what it felt like to experience our service prior to these changes and identified that queuing and lack of privacy at reception were particular areas of concern.

\section{What did we want to achieve and how?}

We wanted to redesign the service in order to simplify the service user pathway; however, no ready-made information technology system was available that would incorporate self-registration, queue management, triage and selfservice access to condoms, pregnancy tests, and chlamydia and gonorrhoea screening kits. Working closely with staff and service users, we therefore developed a new, bespoke system based on touch screens with our technology partner, Key Technology Solutions, which was introduced into the centre in June 2007. This is the first system of its kind to be used in any sexual health service.

\section{How does it work?}

Service users no longer register or complete paperwork at reception. Instead, multiple touch-screen registration kiosks around the waiting area enable users to register and choose from a menu of services available (Figure 1). Users select the reason(s) for visit relevant to them and are then triaged by the system into a queue for the appropriate heath care professional (i.e. client support worker, nurse or doctor). A ticket with the queue number is dispensed from the same registration kiosk and plasma screens in the waiting area display information about queue position as well as displaying rolling health promotion and service messages.

The same system also supports users who choose to manage some of their needs themselves by clearly identifying when self-service is an option and providing the tokens required for the free self-service vending machine that dispenses condoms, pregnancy tests, and self-test chlamydia and gonorrhoea kits. This vending machine is situated in the public area in the centre.

The introduction of touch-screen information points in the same area enable users to access sexual health information electronically rather than simply via leaflets.

We have also introduced a new Client Support Worker (CSW) role that was specifically developed to create an important 'front-of-house presence' in the public areas of the centre. Our CSWs meet and greet users as they arrive and are available to support them with the registration process and use of the vending machine.

\section{J Fam Plann Reprod Health Care 2008; 34(4): 268}

Reproductive and Sexual Health, King's College Hospital NHS Foundation Trust, London, UK

Rachel.Paxford-Jenkins, Service Manager

Usha Kumar, MRCOG, MFSRH, Consultant

Correspondence to: Dr Usha Kumar, Reproductive and Sexual Health, King's College Hospital NHS Foundation Trust, 100 Denmark Hill, Camberwell, London SE5 9RS, UK.

E-mail: Usha.Kumar@kch.nhs.uk

\section{What benefits does the new system offer? To service users}

User involvement has been essential to the redesign of our service. We used feedback from focus groups with service users to fine tune the new system to ensure that it was clear and easy to use. Subsequent mystery shopper visits and other user feedback including a satisfaction survey, interviews with users who used self-service options, and comment forms clearly indicated that users were happy using the new touch-screen technology and many preferred this to the old way of registering. Some 304 user satisfaction surveys (609 distributed; a $49.9 \%$ response rate) were completed in September 2007. Almost all the respondents (98\%) found the self-registration kiosks easy to use; $81 \%$ found the system confidential and $80 \%$ preferred this system to a traditional reception desk. Most service users $(90 \%)$ rated the service as excellent or good and $96 \%$ of them would recommend the new centre to a friend.

\section{To staff}

Reception staff no longer have to manage queues of users waiting to register. Clinical staff can easily identify reasons for attendance of service users before starting a consultation, and the system automatically triages to maximise efficient and appropriate use of the available skill-mix of a multidisciplinary team.

\section{What next?}

Further improvements in progress include generation of activity reports including waiting and transit times, reasons for visits and statutory reports such as KT31. We are also exploring ways of introducing electronic medical records that will link into our new system. The system could also be made available in languages other than English.

\section{Acknowledgements}

The authors would like to acknowledge the support of the Sexual Health Modernisation Initiative Programme funded by the Guy's \& St Thomas' Charitable Trust and their technology partner, Key Technology Solutions, who provided the system. They would also like to acknowledge the Camberwell Sexual Health Centre team for their involvement in the implementation of the new system.

\section{Reference}

1 Sexual Health Modernisation Initiative. Mystery Shopping in Sexual Health - A Toolkit for Delivery. 2008. http://www. gsttcharity.org.uk/pdfs/mystery.pdf [Accessed 11 August 2008].

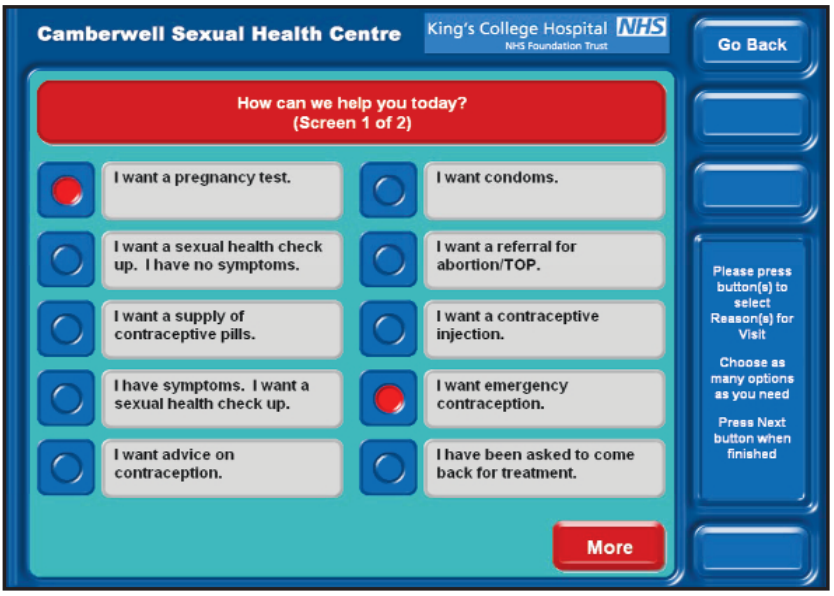

Figure 1 Touch-screen menu giving reasons for visit (Screen 1 of 2 ) 